\title{
Triggering Risk Factors for Stroke: A Case Crossover Study from a Tertiary Care Hospital in Northwest India
}

\section{Sushil Razdan', KK Pandita ${ }^{2}$ and Sunil Kumar Raina ${ }^{3 *}$}

${ }^{1}$ Professor, Department of Neurology, Acharya Shri Chander College of Medical Sciences, Jammu, India

${ }^{2}$ Associate Professor, Department of Internal Medicine, Acharya Shri Chander College of Medical Sciences, Jammu, India

${ }^{3}$ Associate Professor, Department of Community Medicine, Dr. Rajendra Prasad Government Medical College, Tanda, Kangra, India

\begin{abstract}
Introduction: The role of traditional risk factors in the pathophysiology of stroke (IS) has been established and is well know. It has recently been shown that 10 risk factors are associated with $90 \%$ of the risk of stroke.

Material and methods: A case-crossover study design was used for the purpose of study. 2-hour hazard period immediately before the onset of stroke was compared with the 2-hour control period at the same time on the day before the onset of stroke.

Results: The study assessed the role of seven potential triggers for stroke. Forty four patients $(73 \%)$ reported exposure to at least one potential triggering factor during the 2 hours hazard period before onset of stroke symptoms. Twenty nine patients $(66 \%)$ reported exposure to at least one of three (Anger, sudden change in posture, negative emotions) potential triggers during the 2-hour hazard period.
\end{abstract}

Discussion: The current study examined possible association between exposure to potential triggers during a defined hazard period and triggering of the acute onset of stroke. There have been previously reported observations on the potential effect of emotions as a trigger for Ml.

Conclusion: The period of study and the study sample may not be large enough for extrapolation but nevertheless does open up a new area for research in our setup.

Keywords: Triggers; Stroke; Cross-over study

\section{Introduction}

Traditional risk factors have a role to play in the pathophysiology of stroke (Ischemic Stroke). This is now well established [1]. Recent studies have shown that 10 risk factors are associated with $90 \%$ of the risk of stroke [2]. Inspite of this, it is impossible to predict when a stroke will occur, even in people with a high-risk profile [3]. The patterned occurrence with a morning peak of Ischemic Stroke onset strongly suggest that the disease does not occur randomly [4,5]. Further, it has been hypothesized that vascular events could be precipitated by acute factors, called triggers, which may directly lead to its onset $[4,6,7]$.

Studies conducted on role of triggers, have already demonstrated the role of heavy physical exertion [8], anger, [8] emotional and mental stress [9], sexual activity [10], or acute infection [11,12] on myocardial infarction (MI) occurrence [13]. These factors are speculated to qualitatively alter the stable or quiescent phase of coronary atherosclerosis and initiate a cascade of events that culminates in plaque rupture and thrombosis leading to acute MI [7]. In contrast to this, the role of triggers on the occurrence of Ischemic Stroke is less well established and needs to be researched further [14].

The study was conducted using a case-crossover design. The basic advantage with this study design is that each patient serves as his or her own control, thereby eliminating the problem of confounding by differences in constant subject characteristics of cases and controls [15].

\section{Material and Methods}

The study was conducted on patients presenting with stroke to the department of neurology of a tertiary care hospital of Jammu district of Jammu and Kashmir in India. The study was conducted for a period of two months. All patients presented to the department with stroke were considered for inclusion in the study.

\section{Patient selection}

Inclusion criteria: Patients hospitalized for stroke or transient ischemic attacks (TIA), diagnosed according to accepted clinical criteria $[16,17]$, were included.

Patients with recurrent strokes were eligible if they had no previous significant disability (modified Rankin scale - 2), and no more than two previous ischemic events, the last one 6 months or more before the present event.

Exclusion criteria: Patients with known dementia or aphasia and patients scoring 24 or less on the Mini-Mental State Examination (MMSE) were excluded. Patients who first recognized the symptoms of stroke upon awakening were ineligible for this study.

Design: The study design was case-crossover. A total of $26 \mathrm{hrs}$ before the onset of stroke was the study design frame for conduct of this study. This 26-hour period before the onset of stroke was treated in the interview as one long hazard. This was similar to a study conducted on triggers for MI [18]. Detailed data about exposures to potential triggers during the 26 hours before the onset of stroke was recorded. A 2-hour hazard period immediately before the onset of IS was compared with the 2-hour control period at the same time on the day before the

*Corresponding author: Dr. Sunil Kumar Raina, Department of Community Medicine, Dr. R.P. Government Medical College, Tanda, India, Tel: +91 9418061066; E-mail: ojasrainasunil@yahoo.co.in

Received October 16, 2012; Accepted December 31, 2012; Published January 03, 2012

Citation: Razdan S, Pandita KK, Raina SK (2013) Triggering Risk Factors for Stroke: A Case Crossover Study from a Tertiary Care Hospital in Northwest India J Neurol Disord 1: 101. doi:10.4172/2329-6895.1000101

Copyright: @ 2013 Razdan S, et al. This is an open-access article distributed under the terms of the Creative Commons Attribution License, which permits unrestricted use, distribution, and reproduction in any medium, provided the original author and source are credited. 
onset of stroke. The interview for this purpose was conducted by a team comprising of neurologist and epidemiologist. Effort was made to elicit information from the patient with regard to potential trigger effects by direct interview. The information was corroborated by conducting an interview with the nearest relative of the patient, who had been with the patient for last two days.

\section{Questionnaire}

Interviews were conducted 1 to 4 days after stroke onset using a questionnaire especially designed for this purpose. The questionnaire included details on possible exposure to potential triggers and included negative and positive emotions, anger, sudden posture changes as response to a startling event, heavy physical exertion, heavy eating, and sudden temperature changes was assessed for the 2-hour hazard period and for the control periods.

Physical exertion was categorized based on subject's assessment [18]. Emotional stress was measured using the PANAS scale [19]. The scale had to be culturally and linguistically acceptable to the study population. So we modified PANAS scale by means of a systemic, iterative process. The process was similar to the one used by us in a previous study on a migrant population [20].

Average negative emotion scores were calculated for the nine negative items in the five level PANAS for each patient during the hazard and control periods. The methodology was similar as in study conducted previously on MI [21]. Patients were asked to recall any sudden change in posture during the day preceding stroke onset. For each reported sudden change in posture, the exact time and reason were specified.

Only patients reporting sudden changes in posture in response to a startling event, such as getting up suddenly from bed in response to a triggering event were considered exposed.

\section{Results}

A total of 61 individuals admitted in the department of neurology for stroke during the three month study period were included in the study. $46 \%$ (28) men with mean age $63.8 \pm 13.1$ and $54 \%$ (33) women with mean age $60.9 \pm 13.5$ were included in the study (Table 1). Out of a total of 61 , information on the time of occurrence could be elicited on 54 patients only. In 5 male and 2 female patients, the time of onset stroke was not available. Majority of patients (72\%) reported that the time of occurrence of event was before $4 \mathrm{pm}$ (Table 2).

Exposure to seven potential triggers was assessed, as previously described. Forty four patients (73\%) reported exposure to at least one potential triggering factor during the 2 hours hazard period before onset of stroke symptoms. Twenty nine patients (66\%) reported exposure to at least one of three (Anger, sudden change in posture,

\begin{tabular}{|l|l|l|l|l|l|l|}
\hline $\begin{array}{l}\text { Age } \\
\text { group }\end{array}$ & $\mathbf{n}(\%)$ & \multicolumn{3}{|l|}{ Mean age (years) \pm std. deviation } \\
\hline $35-44$ & Male & Female & Total & Male & Female & Total \\
\cline { 2 - 7 } & $2(3.3 \%)$ & $4(6.6 \%)$ & $6(9.8 \%)$ & $36.0 \pm 0.0$ & $41.0 \pm 1.2$ & $39.3 \pm 2.7$ \\
\hline $45-54$ & $4(6.6 \%)$ & $9(14.8 \%)$ & $13(21.3 \%)$ & $50.5 \pm 2.5$ & $50.4 \pm 2.13$ & $50.5 \pm 2.1$ \\
\hline $55-64$ & $5(8.2 \%)$ & $7(11.5 \%)$ & $12(19.7 \%)$ & $58.4 \pm 2.2$ & $61.4 \pm 1.4$ & $60.2 \pm 2.3$ \\
\hline $65-74$ & $11(18.0 \%)$ & $8(13.1 \%)$ & $19(31.1 \%)$ & $66.3 \pm 2.3$ & $67.7 \pm 2.4$ & $66.9 \pm 2.4$ \\
\hline $75-84$ & $4(6.6 \%)$ & $3(4.9 \%)$ & $7(11.5 \%)$ & $80.0 \pm 2.3$ & $80.0 \pm 0.0$ & $80.0 \pm 1.6$ \\
\hline$>85$ & $2(3.3 \%)$ & $2(3.3 \%)$ & $4(6.6 \%)$ & $86.0 \pm 0.0$ & $90.0 \pm 0.0$ & $88.0 \pm 2.3$ \\
\hline Total & $28(45.9 \%)$ & $33(54.1 \%)$ & $61(100.0 \%)$ & $63.8 \pm 13.1$ & $60.9 \pm 13.5$ & $62.3 \pm 13.3$ \\
\hline
\end{tabular}

Minimum age: 36 years, Maximum age: 90 years

Table 1: Age and gender wise distribution of cases.

\begin{tabular}{|l|l|l|l|}
\hline Time of onset of stroke episode & Male & Female & Total \\
\hline $4.00 \mathrm{am}-10.00 \mathrm{am}$ & $6(9.8 \%)$ & $7(11.5 \%)$ & $13(21.3 \%)$ \\
\hline $10.00 \mathrm{am}-4.00 \mathrm{pm}$ & $13(21.3 \%)$ & $11(18.0 \%)$ & $24(39.3 \%)$ \\
\hline $4.00 \mathrm{pm}-10.00 \mathrm{pm}$ & $3(4.9 \%)$ & $9(14.7 \%)$ & $12(19.6 \%)$ \\
\hline $10.00 \mathrm{pm}-4.00 \mathrm{am}$ & $1(1.6 \%)$ & $2(3.3 \%)$ & $3(4.9 \%)$ \\
\hline
\end{tabular}

${ }^{*}$ In 5 male and 2 female cases the time of onset stroke was not available.

Table 2: Distribution of patients according to time of onset of stroke episode.*

negative emotions) potential triggers during the 2-hour hazard period. Ten patients (23\%) reported exposure to more than one potential triggers during the 2-hour hazard period. The most common potential trigger during the 2-hour hazard period was reported to be sudden change in posture (11 patients, $25 \%)$. This was followed by negative emotion (10 patients, 23\%).

\section{Discussion}

The present study examined a possible association between exposure to potential triggers during a defined hazard period and triggering of the acute onset of stroke. Almost $66 \%$ of patients reported exposure to at least one potential trigger. In a previous study, a sharp rise in incidence of AMI and sudden death in Israel was noted during the first days of the Gulf War compared to control periods [22] and increased risk of cardiovascular events was reported during earthquakes [23,24].

Similarly, important sporting events were reported to provide sufficient levels of stress to trigger AMI and stroke [25]. What is known is that brief episodes of mental stress, similar to those encountered in everyday life, may cause transient endothelial dysfunction [26] and induction of coagulation abnormalities by acute stress. A study on triggering of AMI by selected emotions found that feelings of tension, frustration, and sadness could more than double the risk of myocardial ischemia in the subsequent hour. Positive emotions had no significant influence on the risk of myocardial ischemia [27]. It is possible that negative emotions evoke more intense reactions. A significantly elevated relative risk of acute onset of stroke was associated with reported anger. Eighteen percent of the patients reported anger. This percentage is higher than reported in the Stroke Onset Pilot Study, according to which $4 \%$ of the patients had an angry outburst during the 24 hours before stroke onset [28].

Reported sudden changes in body posture in response to a startling event immediately before stroke onset are the most important potential triggers according to our findings. Squatting induces rises in blood pressure and was suggested to be a triggering factor for stroke onset [29]. A study on potential precipitating factors of the onset of AMI reported that $21 \%$ of the patients were exposed to a sudden body position change in the 30 -minute period preceding the cardiac event onset [30]. The most frequent posture changes were from supine or sitting to standing, as in the present study. The proposed triggering mechanism for AMI includes changes in platelet aggregation and fibrinolytic activity [31]. Potential mechanisms for triggering stroke may include in part sympathetic nervous system hyperactivity, hemodynamic effects, and deleterious endothelial effects.

\section{Limitations}

A potential limitation of such a study design is recall bias. Patients might interpret exposures temporally related to onset of symptoms as potential causes for stroke. In this case, the accuracy of reports for the hazard and control periods may differ. For this reason the whole 26hour period preceding the stroke onset was treated as a long hazard period. 
Citation: Razdan S, Pandita KK, Raina SK (2013) Triggering Risk Factors for Stroke: A Case Crossover Study from a Tertiary Care Hospital in Northwest India. J Neurol Disord 1: 101. doi:10.4172/2329-6895.1000101

\section{References}

1. Goldstein LB, Adams R, Alberts MJ, Appel LJ, Brass LM, et al. (2006) Primary prevention of ischemic stroke: a guideline from the American Heart Association/American Stroke Association Stroke Council: cosponsored by the Atherosclerotic Peripheral Vascular Disease Interdisciplinary Working Group; Cardiovascular Nursing Council; Clinical Cardiology Council; Nutrition, Physical Activity, and Metabolism Council; and the Quality of Care and Outcomes Research Interdisciplinary Working Group. Circulation 113: e873-e923.

2. O'Donnell MJ, Xavier D, Liu L, Zhang H, Chin SL, et al. (2010) Risk factors for ischaemic and intracerebral haemorrhagic stroke in 22 countries (the INTERSTROKE study): a case-control study. Lancet 376: 112-123.

3. Guiraud V, Amor MB, Mas JL, Touzé E (2010) Triggers of ischemic stroke : a systematic review. Stroke 41: 2669-2677.

4. Muller JE, Abela GS, Nesto RW, Tofler GH (1994) Triggers, acute risk factors and vulnerable plaques: the lexicon of a new frontier. J Am Coll Cardiol 23 809-813.

5. Stergiou GS, Vemmos KN, Pliarchopoulou KM, Synetos AG, Roussias LG, et al. (2002) Parallel morning and evening surge in stroke onset, blood pressure, and physical activity. Stroke 33: 1480-1486.

6. Stone PH (2004) Triggering myocardial infarction. N Engl J Med 351: 1716 1718.

7. Tofler GH, Muller JE (2006) Triggering of acute cardiovascular disease and potential preventive strategies. Circulation 114: 1863-1872.

8. Strike PC, Perkins-Porras L, Whitehead DL, McEwan J, Steptoe A (2006) Triggering of acute coronary syndromes by physical exertion and anger: clinical and sociodemographic characteristics. Heart 92: 1035-1040.

9. Rosengren A, Hawken S, Ounpuu S, Sliwa K, Zubaid M, et al. (2004) Association of psychosocial risk factors with risk of acute myocardial infarction in 11119 cases and 13648 controls from 52 countries (the INTERHEART study): case-control study. Lancet 364: 953-962.

10. Moller J, Ahlbom A, Hulting J, Diderichsen F, de Faire U, et al. (2001) Sexual activity as a trigger of myocardial infarction. A case-crossover analysis in the Stockholm Heart Epidemiology Programme (SHEEP). Heart 86: 387-390.

11. Clayton TC, Thompson M, Meade TW (2008) Recent respiratory infection and risk of cardiovascular disease: case-control study through a general practice database. Eur Heart J 29: 96-103.

12. Smeeth L, Thomas SL, Hall AJ, Hubbard R, Farrington P, et al. (2004) Risk of myocardial infarction and stroke after acute infection or vaccination. $\mathrm{N}$ Engl J Med 351: 2611-2618.

13. Culic $V$, Eterovic D, Miric $D$ (2005) Meta-analysis of possible external triggers of acute myocardial infarction. Int J Cardiol 99: 1-8.

14. Elkind MS (2007) Why now? Moving from stroke risk factors to stroke triggers Curr Opin Neurol 20: 51-57.

15. Maclure M (1991) The case-crossover design: a method for studying transient effects on the risk of acute events. Am J Epidemiol 133: 144-153.

16. Section 2: Stroke event registration data component (1990) MONICA Manual, Part IV. Event registration.

17. Warlow CP, Morris PJ (1982) Introduction: Transient ischemic attacks. New York: Marcel Dekker

18. Mittleman MA, Maclure M, Tofler GH, Sherwood JB, Goldberg RJ, et al. (1993) Triggering of acute myocardial infarction by heavy physical exertion: protection against triggering by regular exertion. N Engl J Med 329: 1677 1683.

19. Watson D, Clark LA, Tellegen A (1988) Development and validation of brief measures of positive and negative affect: the PANAS scales. J Pers Soc Psychol 54: 1063-1070.

20. Raina SK, Pandita KK, Razdan S (2009) Incidence of dementia in a Kashmiri migrant population. Ann Indian Acad Neurol 12: 154-156.
21. Mittleman MA, Maclure M, Sherwood JB, Mulry RP, Tofler GH, et al. (1995) Triggering of acute myocardial infarction onset by episodes of anger. Determinants of Myocardial Infarction Onset Study Investigators. Circulation 92: $1720-1725$.

22. Meisel SR, Kutz I, Dayan KI, Pauzner H, Chetboun I, et al. (1991) Effect of Iraqi missile war on incidence of acute myocardial infarction and sudden death in Israeli civilians. Lancet 338: 660-661.

23. Brown DL (1999) Disparate effects of the 1989 Loma Prieta and 1994 Northridge earthquakes on hospital admissions for acute myocardial infarction: importance of superimposition of triggers. Am Heart J 137: 830836.

24. Ogawa K, Tsuji I, Shiono K, Hisamichi S (2000) Increased acute myocardial infarction mortality following the 1995 Great Hanshin-Awaji earthquake in Japan. Int J Epidemiol 29: 449-455.

25. Witte DR, Bots ML, Hoes AW, Grobbee DE (2000) Cardiovascular mortality in Dutch men during 1996 European football championship: Iongitudinal population study. BMJ 321: 1552-1554.

26. Ghiadoni L, Donald AE, Cropley M, Mullen MJ, Oakley G, et al. (2000) Mental stress induces transient endothelial dysfunction in humans. Circulation 102: 2473-2478.

27. Gullette EC, Blumenthal JA, Babyak M, Jiang W, Waugh RA, et al. (1997) Effects of mental stress on myocardial ischemia during daily life. JAMA 277: 1521-1526.

28. Mittleman MA, Voetsch B, Caplan LR (2000) Triggers of Ischemic stroke Results from the Stroke Onset Pilot Study. Abstracts of the International Stroke Conference 2001. Stroke 32: 366.

29. Chakrabarti SD, Ganguly R, Chatterjee SK, Chakravarti $A(2002)$ Is squatting a triggering factor for stroke in Indians? Acta Neurol Scand 105: 124-127.

30. Smith M, Little WC (1992) Potential precipitating factors of the onset of myocardial infarction. Am J Med Sci 303: 141-144.

31. Tofler GH, Brezinski D, Schafer Al, Czeisler CA, Rutherford JD, et al (1987) Concurrent morning increase in platelet aggregability and the risk of myocardial infarction and sudden cardiac death. N Engl J Med 316: 15141518. 